\title{
Impact of Team-Based Care on Emergency Department Use
}

Tara Kiran, MD, MSc $\mathrm{c}^{1,2,3,4}$

Rabim Moineddin, $\mathrm{PbD} \mathrm{D}^{2,3}$

Alexander Kopp $p^{3}$

Richard H. Glazier, MD, MPH $H^{1,2,3,4}$

'Department of Family and Community Medicine and the MAP Centre for Urban Health

Solutions, St Michael's Hospital, Toronto,

Ontario, Canada

${ }^{2}$ Department of Family and Community Medicine, Faculty of Medicine, University of Toronto,

Toronto, Ontario, Canada

${ }^{3}$ ICES, Toronto, Ontario, Canada

${ }^{4}$ Institute of Health Policy, Management and Evaluation, University of Toronto, Toronto, Ontario, Canada

Conflicts of interest: Drs Kiran and Glazier work in a Family Health Team. The authors report no other potential conflicts.

\section{CORRESPONDING AUTHOR}

Tara Kiran

MAP Centre for Urban Health Solu-

tions, St Michael's Hospital

Unity Health Toronto

30 Bond $\mathrm{St}$

Toronto, ON Canada M5B 1W8

tara.kiran@utoronto.ca

\begin{abstract}
PURPOSE We sought to assess the impact of team-based care on emergency department (ED) use in the context of physicians transitioning from fee-for-service payment to capitation payment in Ontario, Canada.
\end{abstract}

METHODS We conducted an interrupted time series analysis to assess annual ED visit rates before and after transition from an enhanced fee-for-service model to either a team capitation model or a nonteam capitation model. We included Ontario residents aged 19 years and older who had at least 3 years of outcome data both pretransition and posttransition $(\mathrm{N}=2,524,124)$. We adjusted for age, sex, income quintile, immigration status, comorbidity, and morbidity, and we stratified by rurality. A sensitivity analysis compared outcomes for team vs nonteam patients matched on year of transition, age, sex, rurality, and health region.

RESULTS We compared 387,607 team and 1,399,103 nonteam patients in big cities, 213,394 team and 380,009 nonteam patients in small towns, and 65,289 team and 78,722 nonteam patients in rural areas. In big cities, after adjustment, the ED visit rate increased by $2.4 \%(95 \% \mathrm{Cl}, 2.2 \%$ to $2.6 \%)$ per year for team patients and $5.2 \%(95 \% \mathrm{Cl}, 5.1 \%$ to $5.3 \%)$ per year for nonteam patients in the years after transition $(P<.001)$. Similarly, there was a slower increase in ED visits for team relative to nonteam patients in small towns $(0.9 \%$ [95\% Cl, $0.7 \%$ to $1.1 \%]$ vs $2.9 \%[95 \% \mathrm{Cl}, 2.8 \%$ to $3.1 \%], P<.001)$ and rural areas $(-0.5 \%$ [95\% Cl, $-0.8 \%$ to $0.2 \%]$ vs $1.3 \%[95 \% \mathrm{Cl}, 1.0 \%$ to $1.6 \%], P<.001)$. Results were much the same in the matched analysis.

CONCLUSIONS Adoption of team-based primary care may reduce ED use. Further research is needed to understand optimal team composition and roles.

Ann Fam Med 2022;20:24-31. https://doi.org/10.1370/afm.2728.

\section{INTRODUCTION}

S trong primary care is the foundation of a high-functioning health care system and is associated with better outcomes, lower costs, and greater equity. ${ }^{1}$ But for the last 2 decades, primary care has been in crisis. An outdated fee-forservice payment system was designed to support care for acute conditions and not the growing number of patients with complex chronic conditions who require long appointments and case management in-between. ${ }^{2} \mathrm{~A}$ rapidly increasing evidence base has made it harder to practice as a generalist physician, ${ }^{3}$ with some estimating that implementing clinical practice guidelines for the 10 most common chronic conditions would take longer than the time available in an average work week. ${ }^{4}$ Electronic health records were supposed to improve efficiency but instead have contributed to physician burnout, a growing problem. ${ }^{5}$

Sharing the care within an interprofessional primary care team and implementing physician payment reform are 2 strategies to simultaneously improve patient care and reduce burnout among family physicians. ${ }^{6,7}$ Team-based care is seen as a central pillar in high-functioning primary care by professional associations and policy experts in both Canada and the United States. ${ }^{8-10}$ Yet, jurisdictions in both countries have been slow to scale up team-based care, ${ }^{11,12}$ in large part because of concerns about return on investment.

Early evaluations found primary care teams had a favorable impact on chronic condition management. ${ }^{13}$ More recently, there have been attempts to understand the effect on health care use and cost. The impact on emergency department (ED) visits has been of particular interest. Patients in the United States and Canada consistently report difficulties in accessing timely primary care with $47 \%$ and $41 \%$, respectively, reporting going to the ED for an issue that could have been addressed by their 
primary care clinician. ${ }^{14}$ The evidence on the impact of teambased care on ED visits has been mixed, ${ }^{15-18}$ however, and in some cases, it is difficult to disentangle from payment reform and other components associated with the patient-centered medical home. ${ }^{19,20}$ Primary care teams can theoretically reduce ED use through improved timeliness of appointments, better chronic condition management, greater care coordination, and support for the social determinants of health. ${ }^{21,22}$

In Ontario, Canada, approximately one-fifth of patients receive team-based primary care as part of a Family Health Team whereby physicians formally enroll patients, are paid via blended capitation, and have mandatory after-hours care. ${ }^{23,24}$ Approximately one-quarter of patients are part of a corresponding practice model that includes blended capitation and mandatory after-hours care but does not include government-funded nonphysician health professionals. We conducted an interrupted time series study to compare changes in ED use between patients who transitioned to a Family Health Team and those who transitioned to a similar practice model that did not involve a team.

\section{METHODS}

\section{Context and Setting}

Ontario is Canada's largest province with a population of 14.7 million in 2020. ${ }^{25}$ All permanent residents have health insurance through the provincial health plan, and necessary physician and hospital visits are free at the point of care. ${ }^{26}$ Ninety-four percent of the population report having a primary care professional, usually a family physician. ${ }^{27}$ Approximately $80 \%$ of patients see a family physician who practices in a Patient Enrolment Model-a set of new physician payment models introduced in the early 2000s that include formal patient enrollment, physicians in administrative groups with shared after-hours coverage, financial incentives, and varying degrees of blended payments. ${ }^{23,24}$ The most common Patient Enrolment Model is the Family Health Organization, in which approximately $70 \%$ of physician payment is by capitation adjusted for age and sex, $10 \%$ by financial incentives and bonuses, and $20 \%$ by fee for service. ${ }^{28}$ The second most common model is the Family Health Group, in which $80 \%$ of payment is by fee for service, $5 \%$ via financial incentives and bonuses, and $15 \%$ via capitation.

About $40 \%$ of Family Health Organizations are part of Family Health Teams whereby physicians and their patients have access to a government-funded extended health care team that can include nurses, nurse practitioners, social workers, dietitians, pharmacists, and other health professionals. Teams decide on the role of the professional, for example, pharmacists may support everything from medication reconciliation to smoking cessation, anticoagulation management, opioid stewardship, and physician education. The size and composition of the extended health care team, whether they are colocated with physicians, and the level of integration with the Family Health Organization is also variable. Family
Health Teams are more likely to be located in rural areas where family physicians spend more time delivering emergency, inpatient, and obstetrical care. There are usually no walk-in clinics in rural areas, and rates of ED use are higher compared with those in urban areas. ${ }^{29}$ Family Health Teams were introduced in 2005 but no new teams have been funded since 2012.

\section{Study Design and Population}

We conducted a longitudinal study to compare the change in the annual ED visit rate for patients whose physician transitioned to a team vs a nonteam capitation practice. We included Ontario residents aged $\geq 19$ years whose physician transitioned from a Family Health Group (enhanced fee-forservice payment) to a Family Health Organization (blended capitation payment) between April 1, 2006 and March 31, 2013 and had a minimum of 3 years of outcome data both before and after transition (the minimum number of time points required for the regression analysis). Some physicians who joined a Family Health Organization applied to and became part of a Family Health Team (team practice), whereas others did not (nonteam practice). We included patients from team practices if their physician joined a Family Health Team within a year of transitioning to a Family Health Organization to allow a clear before-after comparison with patients who transitioned to a Family Health Organization without a team. Patients in both groups needed to be in the respective model for at least 3 years (Supplemental Figure 1).

We used linked administrative data sets to conduct a patient-level analysis comparing outcomes for patients who joined a team practice vs a nonteam practice. These data sets were linked using unique encoded identifiers and analyzed at the ICES, an independent, nonprofit research institute whose legal status under Ontario's health information privacy law allows it to collect and analyze health care and demographic data, without consent, for health system evaluation and improvement. The use of data in this project was authorized under section 45 of Ontario's Personal Health Information Protection Act, which does not require review by a research ethics board.

\section{Data Sources}

For our exposure variable (team vs nonteam care), enrollment tables provided by the Ontario Ministry of Health and LongTerm Care allowed us to assign patients to a family physician as of March 31 of a given year. The National Ambulatory Care Reporting System provided us with patient-level data on ED use, our outcome of interest, for each year of the study. We used the provincial health insurance registry for information on patient age, sex, and postal code. We linked patient postal code to 2006 census data to ascertain patients' neighborhood income quintile. We assessed new registration with provincial health insurance within the last 10 years as a proxy for recent immigration, as we have done previously. ${ }^{30}$ We defined rurality on the urban-rural spectrum using the 
Rurality Index of Ontario (values of 0-9 denote big cities, 10-39 small towns, and 40 and higher rural locations). ${ }^{31} \mathrm{We}$ used the Johns Hopkins Adjusted Clinical Group Software to assess comorbidity using adjusted diagnosis groups (no health care use, 1 to 4,5 to 9 , and $\geq 10$, with higher numbers signifying greater comorbidity) and morbidity using resource utilization bands ( 0 to 5 , with higher numbers signifying greater morbidity). ${ }^{32}$

\section{Statistical Analysis}

We calculated outcome data and descriptive characteristics at the patient level for patients of team and nonteam practices between April 1, 2003 and March 31, 2017. We defined the index date as the date on which the patient's physician transitioned to the team-capitation model or the nonteam capitation model. We decided a priori to stratify our analysis by rurality (big cities, small towns, rural) given rural differences in the ED visit rate and primary care delivery. Depending on the year their physician joined a capitated model, patients contributed 6 to 11 years of outcome data in the period spanning before and after the index date.

Our primary analysis was an unmatched comparison of patients of physicians who transitioned to a team practice vs a nonteam practice. We calculated the crude and adjusted ED visit rate before and after the index date. We adjusted for several potential confounders: patient age, sex, neighborhood income quintile, recent immigration, comorbidity, and morbidity. We used a segmented regression (negative-binomial) analysis to model interrupted time series data, to assess both the immediate step change (change in intercept) and the change in trend (gradual change) in the rate of ED visits after the index date. ${ }^{33}$ We then calculated the difference in change in trend between team and nonteam patients. Next, we conducted a sensitivity analysis, comparing team patients with nonteam patients matched by year of transition, age, sex, rurality, and local health region. We calculated the unadjusted ED visit rate before and after the index date to assess the immediate step change and change in trend in mean ED visits following that date. For all analyses, we calculated 95\% confidence intervals and considered $P$ values of $<.005$ to be significant a priori. Further analytic notes are available in Supplemental Figure 2. All analyses were conducted in SAS Enterprise Guide version 7.15 (SAS Institute Inc).

\section{RESULTS}

In our primary analysis, we compared 387,607 team and $1,399,103$ nonteam patients in big cities, 213,394 team and 380,009 nonteam patients in small towns, and 65,289 team and 78,722 nonteam patients in rural areas (Table 1 ). Nonteam patients had lower comorbidity and morbidity, and were less likely to live in a neighborhood in the lowest income quintile. Urban residents were more likely to be recent registrants with the provincial health plan compared with residents in small towns or rural areas. Most patients' physicians transitioned to the new model by March 31, 2010; the peak year of transition was generally 1 to 2 years later for nonteam patients vs team patients. The number of patients included in the analysis varied in each year before and after the index date (Supplemental Table 2).

The unadjusted mean ED visit rate was more than twice as high at baseline in rural areas compared with urban areas (Figure 1). Before transition, the unadjusted rate was higher for team patients compared with nonteam patients; after transition, the difference in the rate between groups narrowed. In adjusted analysis, the mean ED visit rate was still slightly higher for team patients compared with nonteam patients in both big cities and rural areas, but the difference disappeared 6 years after the index date (Figure $2 \mathrm{~A}$ and Figure $2 \mathrm{C}$ ). In small towns, the rate was similar between team and nonteam patients on the index date but higher for the nonteam group 6 years later (Figure $2 \mathrm{~B}$ ).

Table 2 presents results of the interrupted time series analysis for team and nonteam patients after adjustment for confounders. In big cities, the ED visit rate increased by $2.4 \%$ (95\% CI, $2.2 \%$ to $2.6 \%$ ) per year for the team group and $5.2 \%(95 \% \mathrm{CI}, 5.1 \%$ to $5.3 \%)$ per year for the nonteam group in the years after transition $(P<.001)$. Similarly, patients in teams had a smaller annual increase in ED visits compared with nonteam counterparts in small towns $(0.9 \%$ [95\% CI, $0.7 \%$ to $1.1 \%$ ] vs $2.9 \%$ [95\% CI, $2.8 \%$ to $3.1 \%$ ], $P<.001)$, and they had a decrease in rate in rural areas $(-0.5 \%[95 \% \mathrm{CI}$, $-0.8 \%$ to $0.2 \%$ ] vs $1.3 \%$ [95\% CI, $1.0 \%$ to $1.6 \%$ ], $P<.001)$. The change in annual ED visit rate was $2.9 \%, 2.1 \%$, and $1.8 \%$ higher for the nonteam group compared with the team group in big cities, small towns, and rural areas, respectively $(P$ $<.001$ for each).

The results of our sensitivity analysis comparing matched team and nonteam patients are presented in the Supplemental Appendix Table 1, Table 3, and Figure 3, Table 3, and Figure 3, Table 3, and Figure 3. Despite matching, the ED visit rate was still higher pretransition for the team group. The overall results, however, were similar to those of the primary analysis. The change in the annual ED visit rate was $2.0 \%, 1.5 \%$, and $3.3 \%$ higher after transition for nonteam patients compared with team counterparts in big cities, small towns, and rural areas, respectively $(\mathrm{P}<.001$ for each).

\section{DISCUSSION}

We analyzed data for more than 2 million patients comparing ED use before and after their physician transitioned from a fee-for-service model to either a model with blended capitation plus an interprofessional care team or a model with blended capitation only. We found an overall increase in ED use in the time period following the transition for both groups, but there was less of an increase for patients in the team vs the nonteam model. Results were consistent using 2 analytic methods. Findings were similar in big cities, small towns, and rural areas despite differences in baseline ED visit rates by rurality. 
Table 1. Characteristics of Patients Enrolled With Physicians Who Transitioned to Team Capitation and Nonteam Capitation Between 2007 and 2013, Stratified by Rurality

\begin{tabular}{|c|c|c|c|c|c|c|c|}
\hline Characteristic & $\begin{array}{c}\text { Total } \\
(\mathrm{N}=2,524,124)\end{array}$ & $\begin{array}{c}\text { Team } \\
(n=387,607)\end{array}$ & $\begin{array}{c}\text { Nonteam } \\
(n=1,399,103)\end{array}$ & $\begin{array}{c}\text { Team } \\
(n=213,394)\end{array}$ & $\begin{array}{c}\text { Nonteam } \\
(n=380,009)\end{array}$ & $\begin{array}{c}\text { Team } \\
(n=65,289)\end{array}$ & $\begin{array}{l}\text { Nonteam } \\
(n=78,722)\end{array}$ \\
\hline \multicolumn{8}{|l|}{ Age group, No. (\%) } \\
\hline 19-44 years & $1,064,120(42.2)$ & $185,101(47.8)$ & $598,969(42.8)$ & $82,145(38.5)$ & $146,004(38.4)$ & $24,147(37.0)$ & $27,754(35.3)$ \\
\hline $45-64$ years & $967,324(38.3)$ & $135,925(35.1)$ & $531,538(38.0)$ & 85,103 (39.9) & $154,357(40.6)$ & $26,514(40.6)$ & $33,887(43.0)$ \\
\hline Female, No. (\%) & $1,392,513(55.2)$ & $223,637(57.7)$ & $770,943(55.1)$ & $117,335(55.0)$ & $203,019(53.4)$ & $36,163(55.4)$ & $41,416(52.6)$ \\
\hline \multicolumn{8}{|l|}{ Morbidity, No. (\%) } \\
\hline O RUB (none) & $83,116(3.3)$ & $9,432(2.4)$ & $48,766(3.5)$ & $6,661(3.1)$ & $13,594(3.6)$ & $1,712(2.6)$ & $2,951(3.7)$ \\
\hline 1 RUB & $117,770(4.7)$ & $16,954(4.4)$ & $65,169(4.7)$ & $9,620(4.5)$ & $19,236(5.1)$ & $2,941(4.5)$ & $3,850(4.9)$ \\
\hline 2 RUB & $397,301(15.7)$ & $60,932(15.7)$ & $217,742(15.6)$ & $32,934(15.4)$ & $62,304(16.4)$ & $10,315(15.8)$ & $13,074(16.6)$ \\
\hline 3 RUB & $1,409,699(55.8)$ & $216,123(55.8)$ & $787,492(56.3)$ & $117,291(55.0)$ & $209,203(55.1)$ & $35,778(54.8)$ & $43,812(55.7)$ \\
\hline No health care use & $83,132(3.3)$ & $9,434(2.4)$ & $48,775(3.5)$ & $6,662(3.1)$ & $13,597(3.6)$ & $1,713(2.6)$ & $2,951(3.7)$ \\
\hline 1-4 ADG (low) & $1,034,648(41.0)$ & $156,831(40.5)$ & $556,057(39.7)$ & $91,078(42.7)$ & $165,481(43.5)$ & $28,966(44.4)$ & $36,235(46.0)$ \\
\hline 5-9 ADG & $1,139,347(45.1)$ & $178,458(46.0)$ & $639,695(45.7)$ & $93,927(44.0)$ & $165,313(43.5)$ & $28,617(43.8)$ & $33,337(42.3)$ \\
\hline$\geq 10$ ADG (high) & $266,997(10.6)$ & $42,884(11.1)$ & $154,576(11.0)$ & $21,727(10.2)$ & $35,618(9.4)$ & $5,993(9.2)$ & $6,199(7.9)$ \\
\hline $\begin{array}{l}\text { Recent immigration (past } \\
10 \text { years), No. (\%) }\end{array}$ & $141,617(5.6)$ & $29,229(7.5)$ & $98,386(7.0)$ & $4,060(1.9)$ & $7,281(1.9)$ & $1,016(1.6)$ & $1,645(2.1)$ \\
\hline \multicolumn{8}{|l|}{ Income quintile, No. (\%) } \\
\hline Q1 (lowest) & $401,788(15.9)$ & $69,877(18.0)$ & $227,491(16.3)$ & $31,298(14.7)$ & 45,227 (11.9) & $14,963(22.9)$ & $12,932(16.4)$ \\
\hline Q2 & $455,529(18.0)$ & $70,199(18.1)$ & $252,220(18.0)$ & $36,878(17.3)$ & $62,199(16.4)$ & $15,838(24.3)$ & $18,195(23.1)$ \\
\hline Q3 & $490,449(19.4)$ & $73,231(18.9)$ & $264,609(18.9)$ & $44,084(20.7)$ & $79,038(20.8)$ & $14,047(21.5)$ & $15,440(19.6)$ \\
\hline Q4 & $558,640(22.1)$ & $84,190(21.7)$ & $298,542(21.3)$ & $51,299(24.0)$ & $98,129(25.8)$ & $10,573(16.2)$ & $15,907(20.2)$ \\
\hline \multicolumn{8}{|l|}{ Year of transition, No. (\%) } \\
\hline $2011-2012$ & $336,868(13.3)$ & $54,795(14.1)$ & $220,486(15.8)$ & $21,703(10.2)$ & $28,312(7.5)$ & $8,393(12.9)$ & $3,179(4.0)$ \\
\hline $2012-2013$ & $118,375(4.7)$ & $22,641(5.8)$ & $75,171(5.4)$ & $6,700(3.1)$ & $9,217(2.4)$ & $2,602(4.0)$ & $2,044(2.6)$ \\
\hline
\end{tabular}

\section{Findings in Context}

Our findings are consistent with the theory and evidence supporting the role of extended health care teams in improving outcomes. ${ }^{21,22}$ There are also other contextual factors that may explain our findings. In Ontario, teams have specific accountabilities related to access and quality improvement as well as paid administrators, shared decision support specialists, and other supports ${ }^{34,35}$ not present in other practices. Some teams have focused efforts specifically on reducing ED use. ${ }^{36}$

Several US studies have assessed the impact of the patient-centered medical home on ED visits, but results have been heterogenous and the addition of teams is one of many changes included in medical home reforms ${ }^{20}{ }^{2} \mathrm{~A}$ few studies, like ours, have tried to isolate the impact of teams. Researchers at Intermountain Healthcare found an association between teams and better chronic care management and decreased ED use. ${ }^{18}$ A study of academic primary care practices in Boston found a reduction in ED visits for those with 2 or more chronic conditions ${ }_{1}^{16}$ while an evaluation in the Veterans Health Administration found a reduction for those more reliant on Veterans Affairs care. ${ }^{17}$ In Canada, a few studies suggest team-based models have led to reductions in ED use in Quebec and Alberta. ${ }^{15,37,38}$ Of note, ED visits have been rising in Ontario for the last decade in part due to an increase in population, aging of the population, and a reduced number of hospital beds per capita. ${ }^{39}$ 


\section{Study Limitations}

Our study has important limitations. First, it is observational not experimental. In our comparison of groups, we adjusted for (or matched on) available patient characteristics, but there may have been unmeasured differences between patients and physicians of team and nonteam practices, especially given that physicians were free to select between models. We noticed a drop in ED visits between the second and first year before transition in some of the adjusted models, but the reason for this drop is unclear. We did not include calendar year in our unmatched analysis, but we have confidence in our findings given similar results in the matched analysis.

Second, our study does not elucidate what components of team-based care are most effective. Team-based practices in Ontario are heterogeneous in terms of the type of health professionals comprising the team, the ratio of team members per patient, and their roles, but these data are not available in administrative data holdings. We also did not have data on team stability and culture, factors that are associated with team effectiveness. ${ }^{40}$
Third, we focused on the outcome of ED visits, which is only one of many important quality measures. An increase in ED visits does not necessarily imply worse-quality care. ${ }^{41}$ Canada has a high ED visit rate, however, compared with other high-income countries, ${ }_{1}^{14,39}$ and relative improvement is desirable. Future research will explore other health system impacts including potential cost savings.

\section{Policy Implications}

Since 2015, the Ontario government has halted expansion of team-based care because of concerns about the return on investment. ${ }^{42}$ Our study, however, suggests primary care teams have led to improvements in ED use, which may be a surrogate for improved chronic care management, a finding consistent with those of other studies. ${ }^{24}$ Lower ED use likely also relates to timely access, although studies from Ontario have indicated a mixed association between teams and access. ${ }^{43}$ Currently, there is a 10 -fold variation in availability of team-based care in regions across Ontario with no correspondence between availability and health care need ${ }^{44}$

Figure 1. Unadjusted mean ED visit rate before and after transition to a capitation model with vs without team care, stratified by rurality.

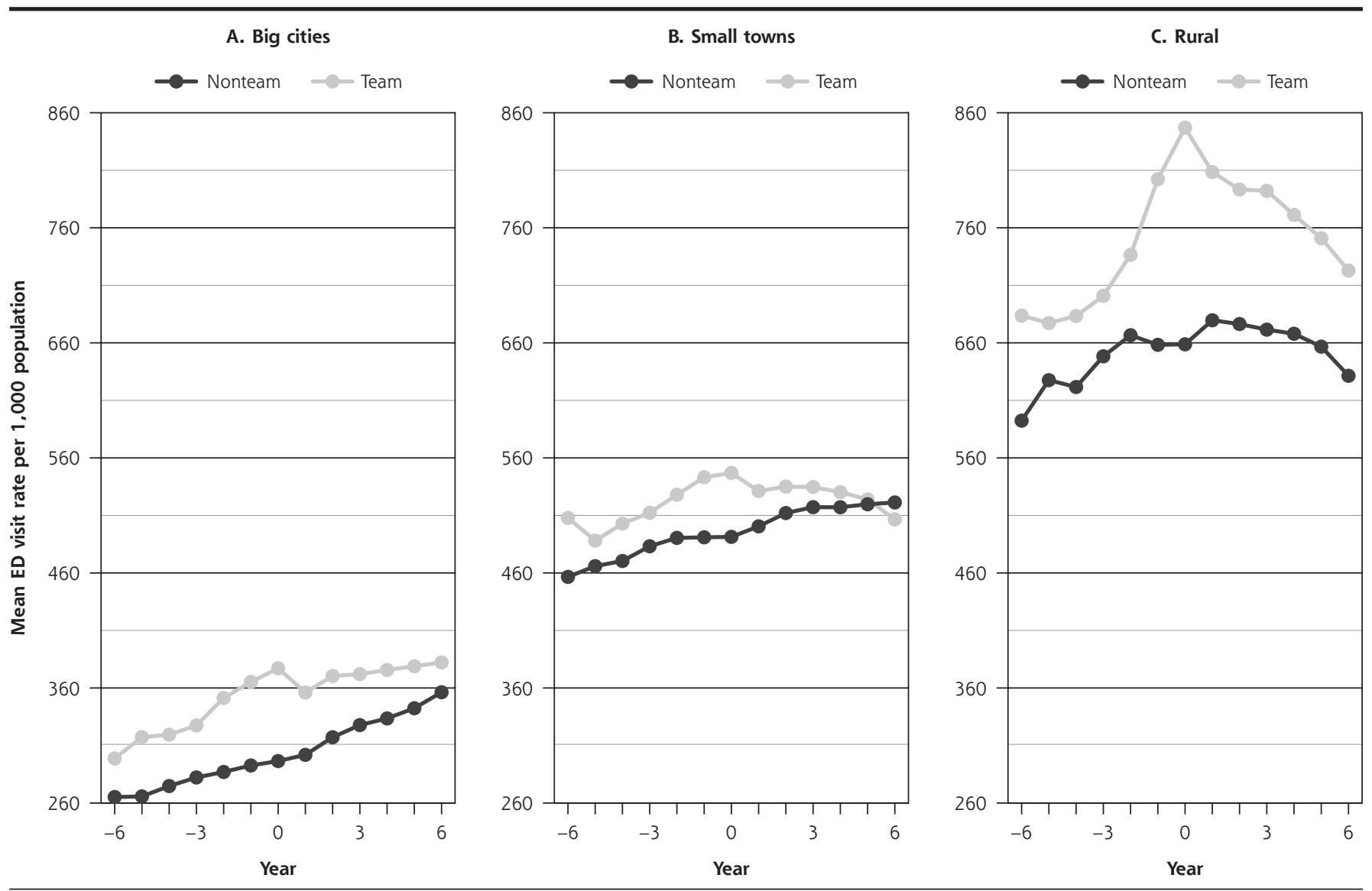

$E D=$ emergency department.

Notes: The 0 value on the $\mathrm{x}$ axis denotes the index date (date on which a patient's physician transitioned to a capitation model). Negative values denote pretransition years; positive values denote posttransition years. 
a manifestation of the inverse care law. ${ }^{45}$ This inequity in access to teams together with our findings and research from other jurisdictions all support government expansion of team-based primary care in tandem with more research to understand the team composition, ratios, and roles associated with better patient outcomes and reduced health system cost.

Figure 2. Adjusted mean ED visit rate before and after transition to a team vs nonteam capitation model, stratified by rurality.

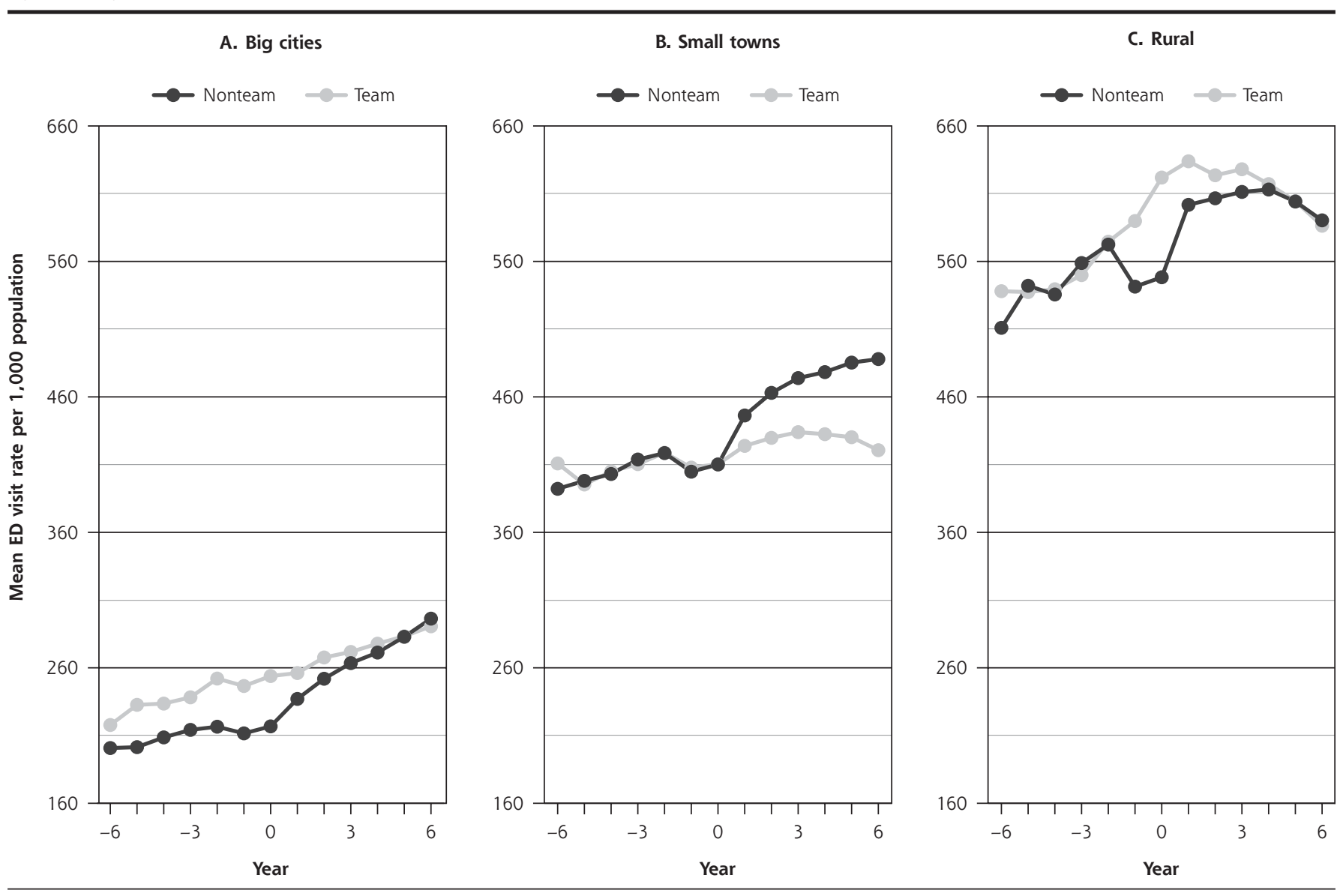

$\mathrm{ED}=$ emergency department.

Notes: The 0 value on the $\mathrm{x}$ axis denotes the index date (date on which a patient's physician transitioned to a capitation model). Negative values denote pretransition years; positive values denote posttransition years. Adjusted for patient's age, sex, neighborhood income quintile, recent immigration, comorbidity, and morbidity.

Table 2. Change in Annual ED Visit Rate With Transition to Capitation, Team vs Nonteam, Stratified by Rurality

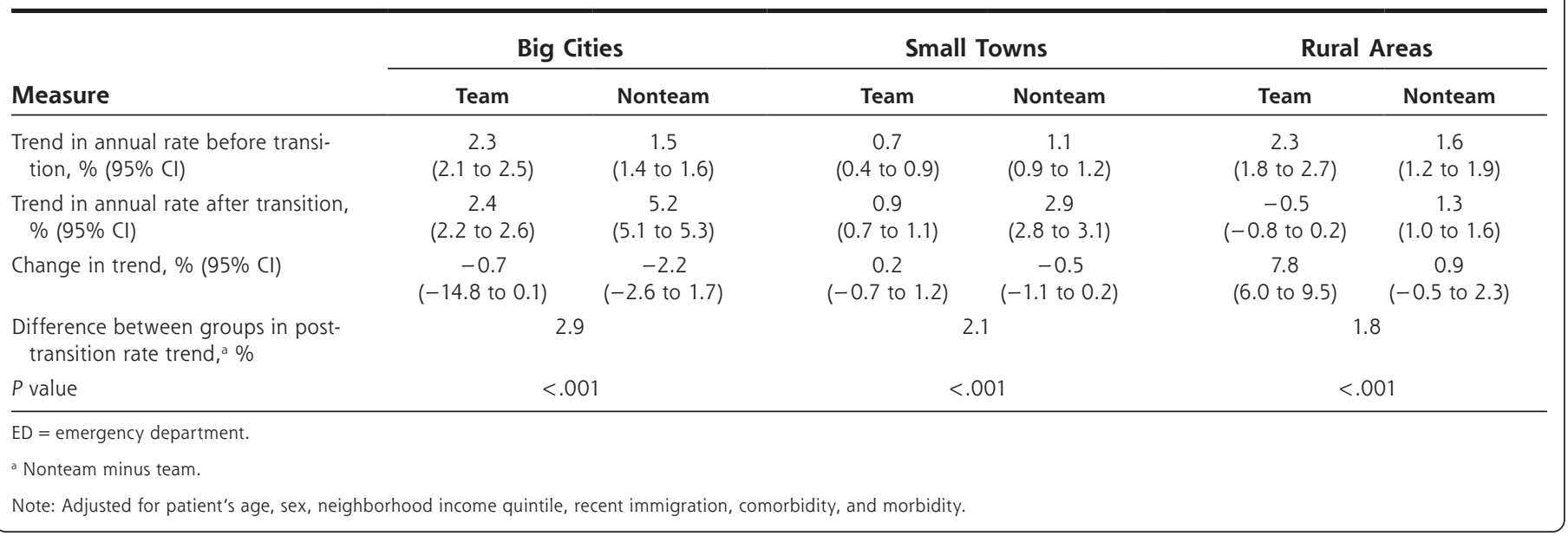


Notably, it may take several years to see improvements in outcomes with expansion of team-based care.

\section{Conclusions}

In summary, we found that patients whose physicians joined a practice model combining capitation and team-based care had a slower increase in ED use compared with those whose physicians joined a capitation model without a team. Our findings add to the growing evidence supporting the value of the extended health care team in primary care.

Read or post commentaries in response to this article.

Key words: primary care; utilization; team-based care; interdisciplinary health team; capitation fee; healthcare financing; physician payment models; emergency department use; patient-centered care; health care reform; health policy; primary care practice models; practice-based research

Submitted November 19, 2020; submitted, revised, May 17, 2021; accepted May 26, 2021.

Author contributions: The authors conceived of and designed the study together. R.M. and A.K. conducted the analysis. All authors helped interpret the data. T.K. drafted the manuscript and all authors critically reviewed it. All authors read and approved the final manuscript.

Funding support: This study was supported by ICES, which is funded by an annual grant from the Ontario Ministry of Health and Long-Term Care (MOHLTC). This study received funding from the INSPIRE Primary Health Care Research Program, which is funded through the Health Systems Research Program of the Ontario Ministry of Health and Long-Term Care. Drs Kiran and Glazier are supported as Clinician Scientists by the Department of Family and Community Medicine at the University of Toronto and at St Michael's Hospital. Dr Kiran is the Fidani Chair of Improvement and Innovation in Family Medicine at the University of Toronto. She is also supported by the Canadian Institutes of Health Research and Health Quality Ontario as an Embedded Clinician Researcher.

Disclaimer: The opinions, results, and conclusions reported in this article are those of the authors and are independent from the funding sources. No endorsement by ICES or the Ontario MOHLTC is intended or should be inferred.

Acknowledgments: We thank Navitha Jayakumar for help in preparing the figures and Lidija Latifovic for performing a literature review and helping us prepare the tables, figures, and manuscript for publication.

Supplemental materials

\section{References}

1. Starfield B, Shi L, Macinko J. Contribution of primary care to health systems and health. Milbank Q. 2005;83(3):457-502. 10.1111/j.1468-0009.2005. 00409.x

2. Upshur RE. Understanding clinical complexity the hard way: a primary care journey. Healthc Q. 2016;19(2):24-28. 10.12927/hcq.2016.24695

3. Pimlott N. Who has time for family medicine? Can Fam Physician. 2008;54(1): 14-16. https://www.cfp.ca/content/54/1/14.long

4. Østbye T, Yarnall KS, Krause KM, Pollak KI, Gradison M, Michener JL. Is there time for management of patients with chronic diseases in primary care? Ann Fam Med. 2005;3(3):209-214. 10.1370/afm.310

5. Sinsky CA, Privitera MR. Creating a "manageable cockpit" for clinicians: a shared responsibility. JAMA Intern Med. 2018;178(6):741-742. 10.1001/ jamainternmed.2018.0575

6. Sinsky CA, Willard-Grace R, Schutzbank AM, Sinsky TA, Margolius D, Bodenheimer T. In search of joy in practice: a report of 23 high-functioning primary care practices. Ann Fam Med. 2013;11(3):272-278. 10.1370/afm.1531

7. Zabar S, Wallach A, Kalet A. The future of primary care in the United States depends on payment reform. JAMA Intern Med. 2019;179(4):515-516. 10.1001/jamainternmed.2018.7623
8. Bodenheimer T, Ghorob A, Willard-Grace R, Grumbach K. The 10 building blocks of high-performing primary care. Ann Fam Med. 2014;12(2):166-171. 10.1370/afm.1616

9. College of Family Physicians of Canada. Patient's medical home. Accessed Jul 27, 2020. https://patientsmedicalhome.ca/

10. Patient Centered Primary Care Collaborative. Joint principles of the patientcentered medical home. Published Mar 7, 2007. Accessed Mar 31, 2015. https://www.aafp.org/dam/AAFP/documents/practice_management/pcmh/ initiatives/PCMHJoint.pdf

11. Fraher EP. Primary care teams: past, present and future. J Am Board Fam Med. 2020;33(4):495-498. 10.3122/jabfm.2020.04.200260

12. College of Family Physicians of Canada. The Patient's Medical Home - Provincial Report Card 2019. College of Family Physicians of Canada; 2019.

13. Bodenheimer T, Wagner EH, Grumbach K. Improving primary care for patients with chronic illness. JAMA. 2002;288(14):1775-1779. 10.1001/ jama.288.14.1775

14. Canadian Institute for Health Information (CIHI). How Canada Compares: Results From the Commonwealth Fund's 2016 International Health Policy Survey of Adults in 11 Countries. $\mathrm{ClHl} ; 2017$.

15. Carter R, Riverin B, Levesque JF, Gariepy G, Quesnel-Vallée A. The impact of primary care reform on health system performance in Canada: a systematic review. BMC Health Serv Res. 2016;16:324. 10.1186/s12913-016-1571-7

16. Meyers DJ, Chien AT, Nguyen KH, Li Z, Singer SJ, Rosenthal MB. Association of team-based primary care with health care utilization and costs among chronically ill patients. JAMA Intern Med. 2019;179(1):54-61. 10.1001/ jamainternmed.2018.5118

17. Reddy A, Wong E, Canamucio A, et al. Association between continuity and team-based care and health care utilization: an observational study of Medicare-eligible veterans in VA patient aligned care team. Health Serv Res. 2018;53(Suppl 3):5201-5218. 10.1111/1475-6773.13042

18. Reiss-Brennan B, Brunisholz KD, Dredge C, et al. Association of integrated team-based care with health care quality, utilization, and cost. JAMA. 2016; 316(8):826-834. 10.1001/jama.2016.11232

19. Green LA, Chang HC, Markovitz AR, Paustian ML. The reduction in ED and hospital admissions in medical home practices is specific to primary care-sensitive chronic conditions. Health Serv Res. 2018;53(2):1163-1179. 10.1111/1475-6773.12674

20. Sinaiko AD, Landrum MB, Meyers DJ, et al. Synthesis of research on patientcentered medical homes brings systematic differences into relief. Health Aff (Millwood). 2017;36(3):500-508. 10.1377/hlthaff.2016.1235

21. Cornell PY, Halladay CW, Ader J, et al. Embedding social workers in Veterans Health Administration primary care teams reduces emergency department visits: an assessment of the Veterans Health Administration program to add social workers to rural primary care teams. Health Aff (Millwood). 2020;39(4): 603-612. 10.1377/hlthaff.2019.01589

22. Ghorob A, Bodenheimer T. Sharing the care to improve access to primary care. N Engl J Med. 2012;366(21):1955-1957. 10.1056/NEJMp1202775

23. Hutchison B, Glazier R. Ontario's primary care reforms have transformed the local care landscape, but a plan is needed for ongoing improvement. Health Aff (Millwood). 2013;32(4):695-703. 10.1377/hlthaff.2012.1087

24. Kiran T, Kopp A, Moineddin R, Glazier RH. Longitudinal evaluation of physician payment reform and team-based care for chronic disease management and prevention. CMAJ. 2015;187(17):E494-E502.

25. Statistics Canada. Population estimates on July 1st, by age and sex. Accessed Apr 5, 2020. https://www150.statcan.gc.ca/t1/tbl1/en/tv.action?pid=171000 0501EpickMembers\%5B0\%5D =1.7EpickMembers\%5B1\%5D =2.1

26. Martin D, Miller AP, Quesnel-Vallée A, Caron NR, Vissandjée B, Marchildon GP. Canada's universal health-care system: achieving its potential. Lancet. 2018;391(10131):1718-1735. 10.1016/S0140-6736(18)30181-8

27. Health Quality Ontario. Measuring Up 2017: A Yearly Report on How Ontario's Health System is Performing. Queen's Printer for Ontario; 2017.

28. Henry DA, Schultz SE, Glazier RH, Bhatia RS, Dhalla IA, Laupacis A. Payments to Ontario Physicians From Ministry of Health and Long-Term Care Sources, 1992/93 to 2009/10: ICES Investigative Report. Institute for Clinical Evaluative Sciences; 2012. 
29. Glazier RHZB, Rayner J. Comparison of Primary Care Models in Ontario by Demographics, Case Mix and Emergency Department Use, 2008/09 to 2009/10: ICES Investigative Report. Institute for Clinical Evaluative Sciences; 2012.

30. Kiran T, Glazier RH, Moineddin R, Gu S, Wilton AS, Paszat L. The impact of a population-based screening program on income- and immigration-related disparities in colorectal cancer screening. Cancer Epidemiol Biomarkers Prev. 2017;26(9):1401-1410. 10.1158/1055-9965.EPI-17-0301

31. Kralj B. Measuring Rurality - RIO 2008_Basic: Methodology and Results. Ontario Medical Association; 2009.

32. The Johns Hopkins University. The Johns Hopkins ACG System. Published 2012. Accessed Mar 27, 2012. https://www.acg.jhsph.org/

33. Bernal JL, Cummins S, Gasparrini A. Interrupted time series regression for the evaluation of public health interventions: a tutorial. Int J Epidemiol. 2017; 46(1):348-355. 10.1093/ije/dyw098

34. Green ME, Harris SB, Webster-Bogaert S, et al. Impact of a provincial quality-improvement program on primary health care in Ontario: a populationbased controlled before-and-after study. CMAJ Open. 2017;5(2):E281-E289. 10.9778/cmajo.20160104

35. Wagner DJ, Durbin J, Barnsley J, Ivers NM. Beyond quality improvement: exploring why primary care teams engage in a voluntary audit and feedback program. BMC Health Serv Res. 2017;17(1):803. 10.1186/s12913-017-2765-3

36. Health Quality Ontario. Primary Care: Impressions and Observations, 2015/16 Quality Improvement Plans. Queen's Printer for Ontario; 2016.

37. McAlister FA, Bakal JA, Green L, Bahler B, Lewanczuk R. The effect of provider affiliation with a primary care network on emergency department visits and hospital admissions. CMAJ. 2018;190(10):E276-E284. 10.1503/ cmaj. 170385
38. Riverin BD, Li P, Naimi Al, Strumpf E. Team-based versus traditional primary care models and short-term outcomes after hospital discharge. CMAJ. 2017; 189(16):E585-E593. 10.1503/cmaj.160427

39. Health Quality Ontario. Under Pressure: Emergency Department Performance in Ontario. Queen's Printer for Ontario; 2016.

40. Bodenheimer T. Anatomy and physiology of primary care teams. JAMA Intern Med. 2019;179(1):61-62. 10.1001/jamainternmed.2018.5550

41. Shojania KG. Are increases in emergency use and hospitalisation always a bad thing? Reflections on unintended consequences and apparent backfires. BMJ Qual Saf. 2019;28:687-692. 10.1136/bmjqs-2019-009406

42. Grant K. Ontario's curious shift away from family health teams. The Globe and Mail. Published Feb 15, 2015. Accessed Mar 25, 2017. https://www.theglobeandmail.com/life/health-and-fitness/health/ ontarios-curious-shift-away-from-family-health-teams/article22989363/

43. Kiran T, Green ME, DeWit Y, et al. Association of physician payment model and team-based care with timely access in primary care: a populationbased cross-sectional study. CMAJ Open. 2020;8(2):E328-E337. 10.9778/ cmajo.20190063

44. Glazier R, Gozdyra P, Kim M, Bai L, Kopp A, Schultz S. Geographic variation in primary care need, service use and providers in Ontario, 2015/16. ICES. Published Aug 2018. Accessed Feb 25, 2021. https://www.ices.on.ca/ Publications/Atlases-and-Reports/2018/Geographic-Variation-in-Primary-Care

45. Hart JT. The inverse care law. Lancet. 1971;1(7696):405-412. 0.1016/ s0140-6736(71)92410-x 